\section{On the Mechanism}

of Selective

co Oxidation

\section{on Nanosized}

$\mathrm{Au} / \boldsymbol{\gamma}-\mathrm{Al}_{2} \mathrm{O}_{3}$ Catalysts

\section{Gavrila,b,, A Georgakab, V Loukopoulos ${ }^{\mathrm{b}}, \mathrm{G}$ Karaiskakis ${ }^{\mathrm{b}}$, B E Nieuwenhuys ${ }^{\mathrm{a}}$}

a Leiden Institute of Chemistry, Leiden University, 2300 RA Leiden, The Netherlands

b Physical Chemistry Laboratory, Department of Chemistry, University of Patras, 26504, Patras, Greece

\begin{abstract}
New findings give further information on the mechanism of carbon monoxide selective oxidation over $\gamma$-alumina supported nanoparticle sized gold catalysts. a) $\mathrm{CO}_{2}$ formation, increasing with rising temperature, is observed in the absence of hydrogen and oxygen pointing to a model of active sites consisting of an ensemble of metallic Au atoms and a cationic Au with a hydroxyl group, b) At high temperatures $\left(>200{ }^{\circ} \mathrm{C}\right)$ in excess of $\mathrm{H}_{2}$, reversed water gas shift (RWGS) reaction results in $\mathrm{CO}_{2}$ consumption towards $\mathrm{CO}$ and $\mathrm{H}_{2} \mathrm{O}$ formation. c) Hydrogen strongly influences the interaction of $\mathrm{CO}$ on $\mathrm{Au} / \gamma-\mathrm{Al}_{2} \mathrm{O}_{3}$, by weakening the $\mathrm{CO}$ adsorption. The presence of hydrogen plays an important role both decreasing the strength of $\mathrm{CO}$ bonding and in the prevention of deactivation and regeneration.
\end{abstract}

\section{Keywords}

Inverse Gas Chromatography, Rate Constants, Au catalysts, $\gamma-\mathrm{Al}_{2} \mathrm{O}_{3}$ supported catalysts, PEM Fuel-cell, Selective $\mathrm{CO}$ oxidation, Hydroxyl groups, Cationic Au.

*Corresponding author

E-mail: D.Gavril@upatras.gr

Current address: Physical Chemistry Laboratory, Department of Chemistry, University of Patras, 26504, Patras, Greece

\section{Introduction}

Nanometer-sized gold particles on oxide supports are efficient catalysts for the selective catalytic oxidation (SCO) of carbon monoxide under conditions compatible with the operation of PEM fuel cells. Nanosized $\mathrm{Au} / \gamma-\mathrm{Al}_{2} \mathrm{O}_{3}$ catalysts are able to oxidize $\mathrm{CO}$ between 20 and $70^{\circ} \mathrm{C}$ in an atmosphere of hydrogen combining high $\mathrm{CO}$ conversion and satisfactory selectivity to $\mathrm{CO}_{2}(1)$. It is generally agreed that the catalytic activity of gold depends on the size of the gold particles, but the nature of support material, the preparation method, the activation procedure have also been suggested to play a key role (2). Sites at the gold support interface have also been claimed to be responsible for the activity in CO oxidation (3). Strain in the Au particles due to the mismatch of the lattices at the interface with the support (4) and the effect of low-coordinated sites and roughness (4) have also been suggested as important factors for high activity. The most important effect, concerning the catalytic activity of gold nanoparticles for low temperature oxidation of $\mathrm{CO}$ is related to the availability of many low-coordinated gold atoms on the small particles (5). Effects related to the interaction with the support may also contribute, but to a considerably smaller extent (5).

CO oxidation over group VIII noble metals is the most studied catalytic reaction. However, selective oxidation of CO in hydrogen-rich conditions is not as well studied $(6,7)$. CO (reactant) and $\mathrm{CO}_{2}$ (product) sorption processes are fundamental elementary steps for SCO and moreover, the effect of hydrogen on their sorption over supported $\mathrm{Au}$ catalysts remains a subject of significant interest.

Among the various supported $\mathrm{Au}$ catalysts, $\mathrm{Au} / \mathrm{Al}_{2} \mathrm{O}_{3}$ is perhaps one that has shown the widest variation for $\mathrm{CO}$ oxidation, ranging from being very inactive to practically as active as $\mathrm{Au} / \mathrm{TiO}_{2}$ (8). Compared to $\mathrm{Au} / \gamma-\mathrm{Al}_{2} \mathrm{O}_{3}$, multicomponent gold-based catalysts also supported on $\gamma-\mathrm{Al}_{2} \mathrm{O}_{3}$ and combined with common metal oxides, such as: $\mathrm{MnO}_{x}, \mathrm{MgO} \mathrm{FeO}_{x}(9,10)$ as well as gold catalysts supported on other materials such as $\mathrm{Au} / \mathrm{TiO}_{2}(11)$ and $\mathrm{Au} / \mathrm{FeO} \mathrm{x}_{\mathrm{x}}(11,12)$ have been found to exhibit even more promising commercial performance for the SCO reaction. However, based on its simplicity, a well-studied $\mathrm{Au} / \boldsymbol{\gamma}-\mathrm{Al}_{2} \mathrm{O}_{3}$ catalyst $(1,9)$ has been utilized in the present work as model system, in order to gain fundamental information on the catalytic behaviour of gold nanoparticles and identify the active sites on $\mathrm{Au} / \gamma-\mathrm{Al}_{2} \mathrm{O}_{3}$.

In this paper, new findings which offer further information concerning the mechanism of $\mathrm{CO}$ preferential oxidation over nanosized $\mathrm{Au}$ are presented. The first finding concerns $\mathrm{CO}_{2}$ formation in the absence of oxygen and hydrogen both in bare $\gamma-\mathrm{Al}_{2} \mathrm{O}_{3}$ as well as in $\mathrm{Au} / \boldsymbol{\gamma}-\mathrm{Al}_{2} \mathrm{O}_{3}$ (called as $\mathrm{CO}$ decomposition). At high temperatures $\left(>200^{\circ} \mathrm{C}\right)$ in excess of $\mathrm{H}_{2}$, over the $\mathrm{Au} / \boldsymbol{\gamma}-\mathrm{Al}_{2} \mathrm{O}_{3}$ catalyst, reversed water gas shift (RWGS) reaction results in $\mathrm{CO}_{2}$ consumption towards $\mathrm{CO}$ and $\mathrm{H}_{2} \mathrm{O}$ formation. Finally, the kinetic measurements of the present work indicate that hydrogen strongly influences the interaction of $\mathrm{CO}$ on $\mathrm{Au} / \gamma-\mathrm{Al}_{2} \mathrm{O}_{3}$, by weakening $\mathrm{CO}$ adsorption. 


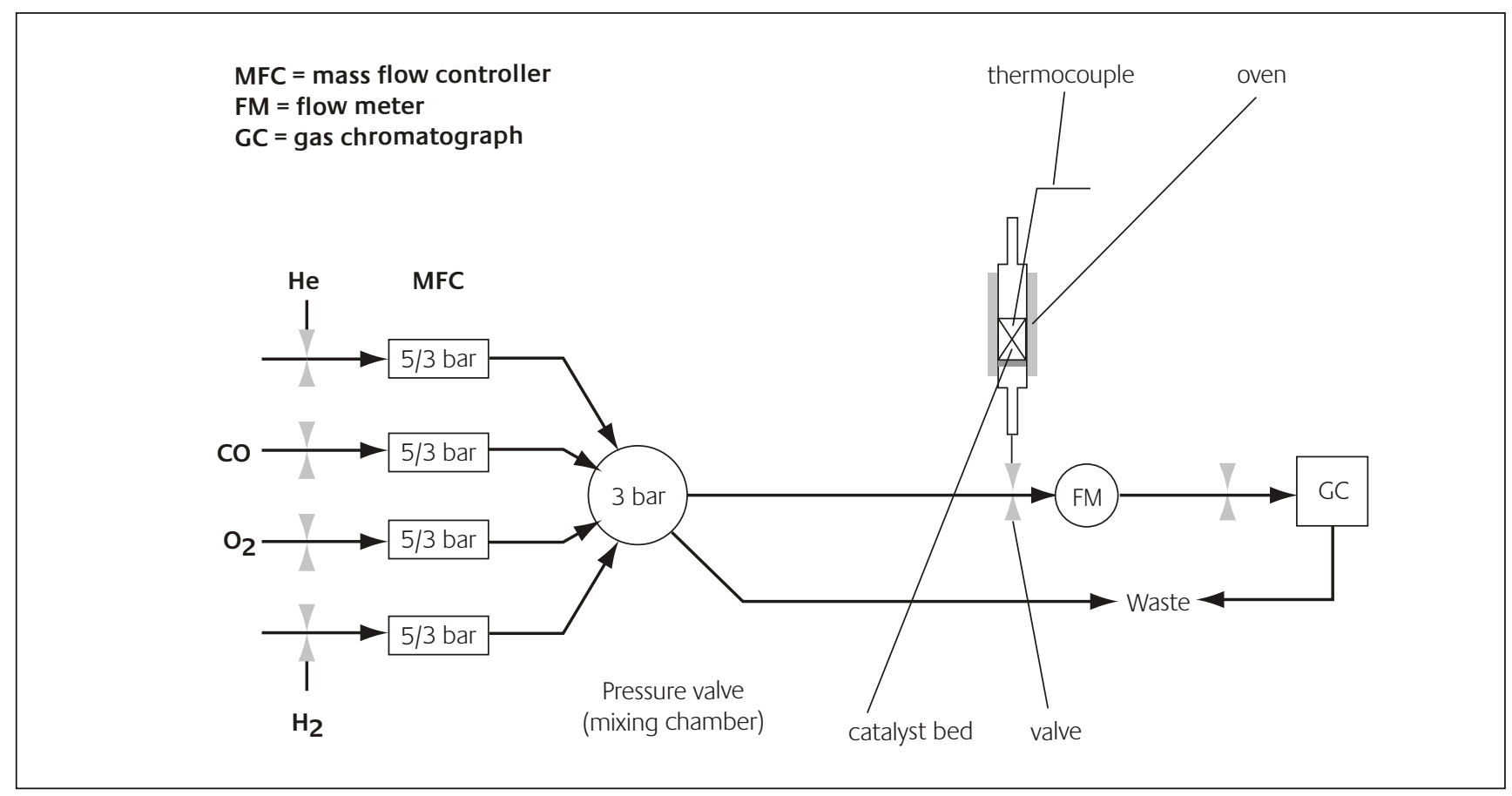

Figure 1

Scheme of the continuous feeding activity experiments set-up

\section{Experimental methods}

\section{Preparation of nanometer size Au catalysts}

The nanometer sized $\mathrm{Au} / \gamma-\mathrm{Al}_{2} \mathrm{O}_{3}$ catalyst with an intended $5 \%$ wt. composition was prepared by homogeneous deposition precipitation with urea. This method leads to the smallest average gold size (3-5 nm). All gold catalysts were filtered, washed to remove $\mathrm{Cl}^{-}$and dried in air at $80^{\circ} \mathrm{C}$ for at least $16 \mathrm{~h}$ and then calcined in a flow of oxygen up to $300^{\circ} \mathrm{C}$ (heating rate $5{ }^{\circ} \mathrm{C}-\mathrm{min}^{-1}$ ). The samples were kept at $300^{\circ} \mathrm{C}$ for $2 \mathrm{~h}$, and then cooled to room temperature. The method of preparation and the surface characterization of the catalyst using AAS, XRD, HRTEM, XPS and MES, have been presented previously $(1,9,10)$.

The gold loading determined by AAS was $5.1 \pm 0.3 \%$, while the mean diameter of the gold particles was measured 4.2 $\mathrm{nm}(\mathrm{XRD})$ and 3.6 $\pm 1.4 \mathrm{~nm}$ (HRTEM), respectively. The gold crystallites were found to sinter in a flow of oxygen at a temperature of $400^{\circ} \mathrm{C}$ and higher in agreement with literature (13). Although XRD, HRTEM and XPS measurements clearly point to the presence of metallic gold, the presence of traces of oxidic gold $\left(\mathrm{Au}_{2} \mathrm{O}\right.$ or $\left.\mathrm{Au}_{2} \mathrm{O}_{3}\right)$ cannot be excluded.

\section{Activity experiments under continuous-flow}

The flow system used for the study of $\mathrm{CO}$ interaction with the studied catalyst is shown in Figure 1. The activity experiments were carried out in a lab-scale flow reactor. Typically $0.20 \mathrm{~g}$ catalyst was used for each reaction. Prior to measurement the catalysts were reduced in-situ in a flow of 4 vol\% $\mathrm{H}_{2} / \mathrm{He}$ at $300^{\circ} \mathrm{C}$ (heating rate $10^{\circ} \mathrm{C}-\mathrm{min}^{-1}$ ) and kept at this temperature for $30 \mathrm{~min}$. A reductive pre-treatment in either $\mathrm{H}_{2}$ or $\mathrm{CO}$ is necessary in order to obtain optimal performance for CO oxidation, which points to an intrinsically higher activity of the reduced gold species. After cooling to room temperature the reactor was purged with helium to remove all of the hydrogen. Subsequently, the reactant flow was introduced. Different activity tests were carried out in the following series: i) $1.2 \%$ vol. $\mathrm{CO}$ in $\sim 70$ vol $\% \mathrm{H}_{2}+\sim 29$ vol\% $\mathrm{He}$, ii) $4 \%$ vol. $\mathrm{CO}$ in $\mathrm{He}$, iii) $2.0 \%$ vol. $\mathrm{CO}+2.0 \%$ vol. $\mathrm{O}_{2}$ in He and iv) $0.6 \%$ vol. $\mathrm{CO}+0.6 \%$ vol. $\mathrm{O}_{2}$ in $\sim 70$ vol\% $\mathrm{H}_{2}+\sim 29$ vol\% He. The total reactant mixture flow rate was $40 \mathrm{ml}^{-\mathrm{min}^{-1}}$. The reactant gases were fed separately to the system with mass flow controllers (Bronkhorst), and led through a small chamber to ensure proper mixing before entering the reactor: Both thermocouple and oven were connected to a temperature controller (Shimaden SR50$2 A E)$, allowing the reaction to be temperature-programmed. The effluent gases were analyzed on-line by a gas chromatograph equipped with a thermal conductivity detector. The experiments were carried out under atmospheric pressure.

XRD measurements of the fresh and spent gold catalyst revealed no sintering of the gold particles $\left(d_{A u, f r e s h}=4.2 \mathrm{~nm}\right)$ after the above activity tests.

\section{Activity/kinetic measurements under non continuous-flow}

Kinetic measurements and complementary activity tests were performed by using the novel gas chromatographic technique of reversed flow gas chromatography. The experimental set-up of RF-GC is presented in Figure 2. In RFGC, another column (diffusion column) is placed perpendicularly in the center of the usual chromatographic column (sampling column). The carrier gas flows 


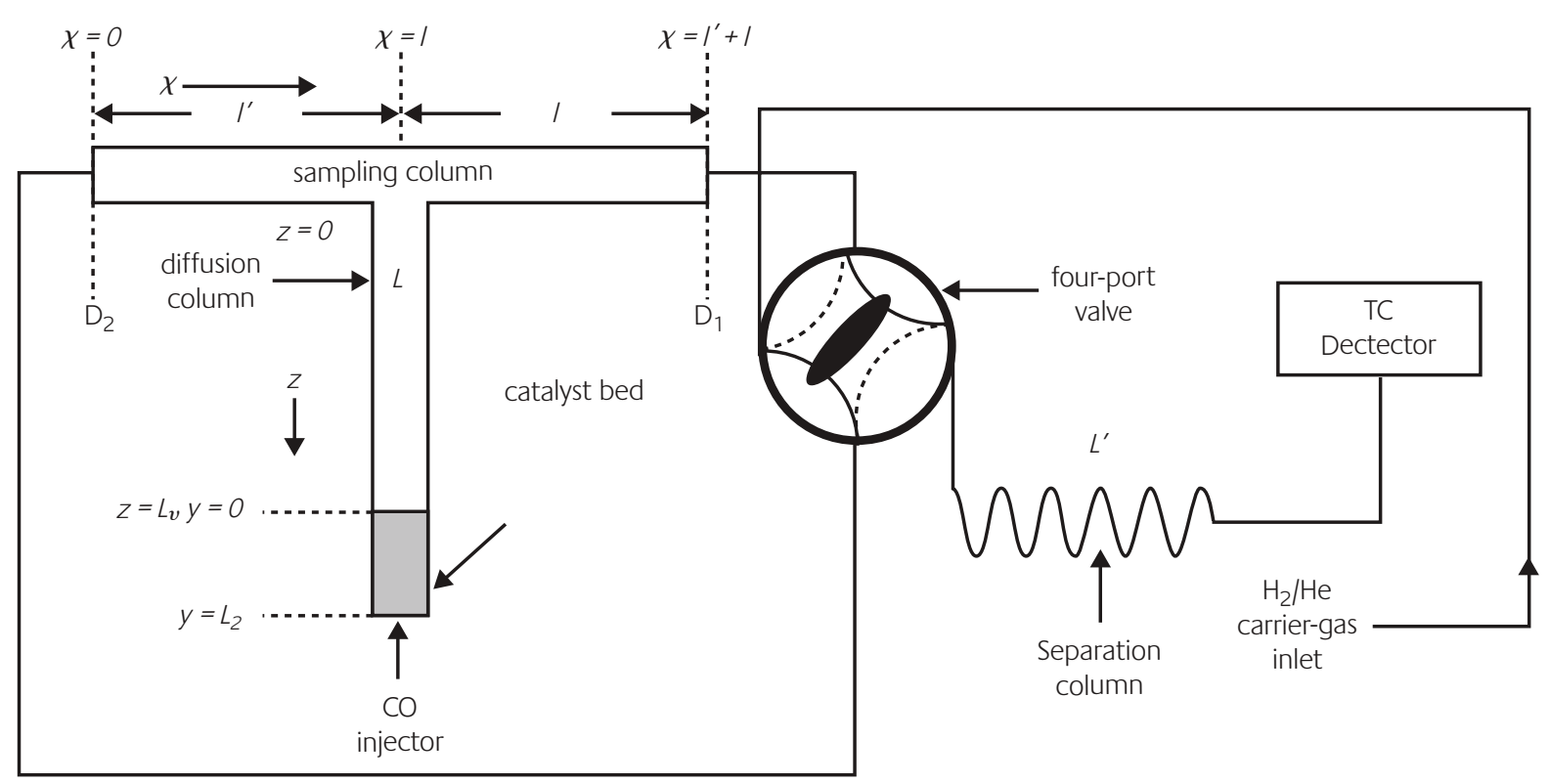

\section{Figure 2}

Experimental setup used for the kinetic investigation of the effect of hydrogen in carbon monoxide sorption over the studied $\gamma$-Al $\mathrm{O}_{3}$ supported Au catalyst, from reversed-flow gas chromatography

continuously through the sampling column, while it is stagnant inside the diffusion column. In contrast with conventional GC, where the mobile phase is the centre of interest, in RF-GC the solid or liquid substance placed into the diffusion column is under investigation, as in the case of inverse gas chromatography. The stationary phase (catalyst bed under study) is placed at the lower closed end of the diffusion column and the displacement of the injected solute (CO) into the diffusion column depends on its interaction with the stationary phase (e.g. adsorption, desorption and surface reaction) as well as its diffusion into the stagnant carrier gas (mobile phase), while it is independent of the carrier gas flow-rate. These features make RF-GC an ideal method not only for activity studies but mainly for kinetic measurements.

Another feature of RF-GC is the sampling procedure of the physicochemical phenomenon, which takes place in the diffusion column. The sampling procedure is carried out by using a four-port valve, enabling reversals of the flow of the carrier gas for a short time, as well as the restoring of its flow in its original direction. The above-mentioned flow reversals procedure results in a brief enrichment of the solute quantity into the carrier gas and thus, extra chromatographic peaks are created on the continuous concentration-time curve (chromatogram). The extra peaks are symmetrical and their height or area is proportional to the concentration of the solute in the junction of the diffusion and sampling columns, giving to RF-GC a higher sensitivity and accuracy, succeeding accurate data collection and limiting the need for computer data reduction.

The estimation of the various kinetic parameters is done from plots of the heights or the areas of the extra chromatographic peaks against the time from solute's injection (which are so-called as Diffusion Bands) and from geometrical characteristics of the diffusion column (such as its length and its volume).

The materials, apparatus and calculations used for the study of carbon monoxide sorption processes under various hydrogen amounts in the gaseous feed, by RF-GC, as well as the advantages of the method have been presented in detail in recent publications (14-17).

\section{Results and discussion}

Critical elementary reaction steps such as $\mathrm{CO}$ and $\mathrm{CO}_{2}$ adsorption, desorption and surface breaking/bonding over Au catalysts can provide substantial insights into catalysis by gold nanoparticles. In the framework of a forthcoming work, the sorption processes of carbon monoxide, oxygen (SCO reactants) and carbon dioxide (SCO product) over nanosized Au supported on $\gamma-\mathrm{Al}_{2} \mathrm{O}_{3}$ have been kinetically studied.

A preliminary study, in which the effect of the gas feed composition on the interaction of $\mathrm{CO}$ with the studied $\mathrm{Au} / \gamma$ $\mathrm{Al}_{2} \mathrm{O}_{3}$ catalyst, was carried out by the continuous feeding setup of Figure 1 (c.f. Experimental Methods section). The most important finding of this study was that the adsorption of $\mathrm{CO}$ over $\mathrm{Au} / \gamma-\mathrm{Al}_{2} \mathrm{O}_{3}$, in the absence of oxygen from the feeding stream, results in $\mathrm{CO}_{2}$ formation (CO decomposition). The experimental data obtained by RF-GC (under non continuous feeding conditions) also ascertained that the adsorption of carbon monoxide on the studied $\mathrm{Au} / \boldsymbol{\gamma}-\mathrm{Al}_{2} \mathrm{O}_{3}$ catalyst, in the absence of hydrogen and oxygen (carrier gas $100 \% \mathrm{He}$ ) results in $\mathrm{CO}_{2}$ formation. Identification of the two sample peaks 
shows that the first peak belongs to the adsorbate $\mathrm{CO}$, while the second one to $\mathrm{CO}_{2}$. The $\mathrm{CO}$ to $\mathrm{CO}_{2}$ conversion, $x$, was chromatographically estimated by utilizing the experimentally measured areas of the reactant $A_{\mathrm{CO}}$ and its product $A_{\mathrm{CO}_{2}}$

$$
x=\frac{R A_{\mathrm{CO}_{2}}}{R A_{\mathrm{CO}_{1}}+A_{\mathrm{CO}}}
$$

where: $R=0.966$, is the relative molar response of the thermal conductivity detector for $\mathrm{CO}_{2}$ to that for $\mathrm{CO}$ under the used experimental conditions. The respective findings are presented in Figures $3 a$ (under continuous feeding conditions) and $3 \mathrm{~b}$ (under non continuous feeding conditions).

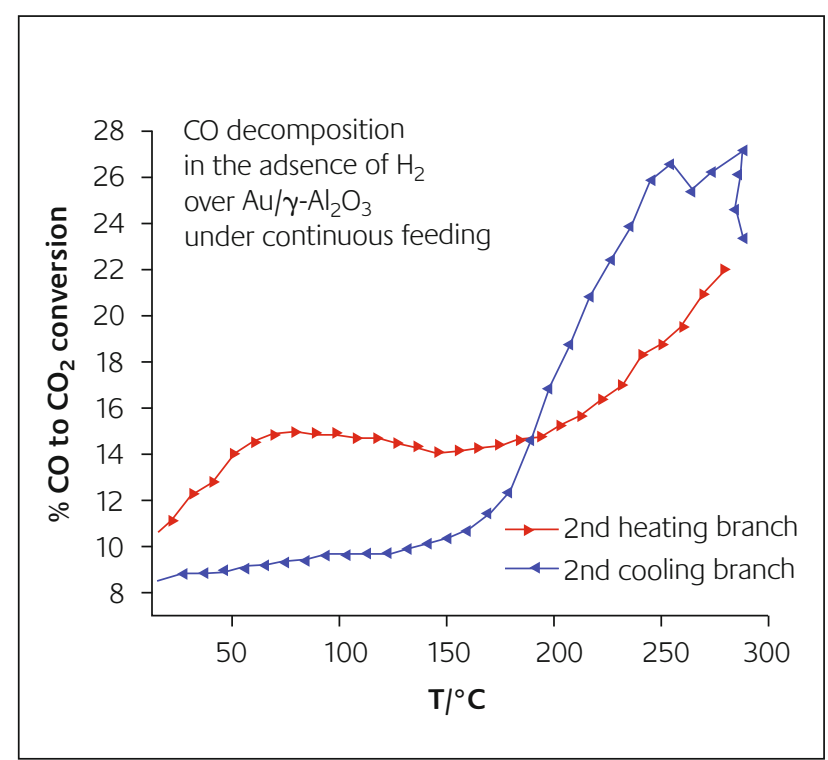

\section{Figure 3a}

a) Heating and cooling branches of the conversion of $\mathrm{CO}$ to $\mathrm{CO}_{2}$ in the absence of oxygen, over the studied $\mathrm{Au} / \boldsymbol{\gamma}-\mathrm{Al}_{2} \mathrm{O}_{3}$ catalyst versus reaction temperature, measured at continuous feeding conditions

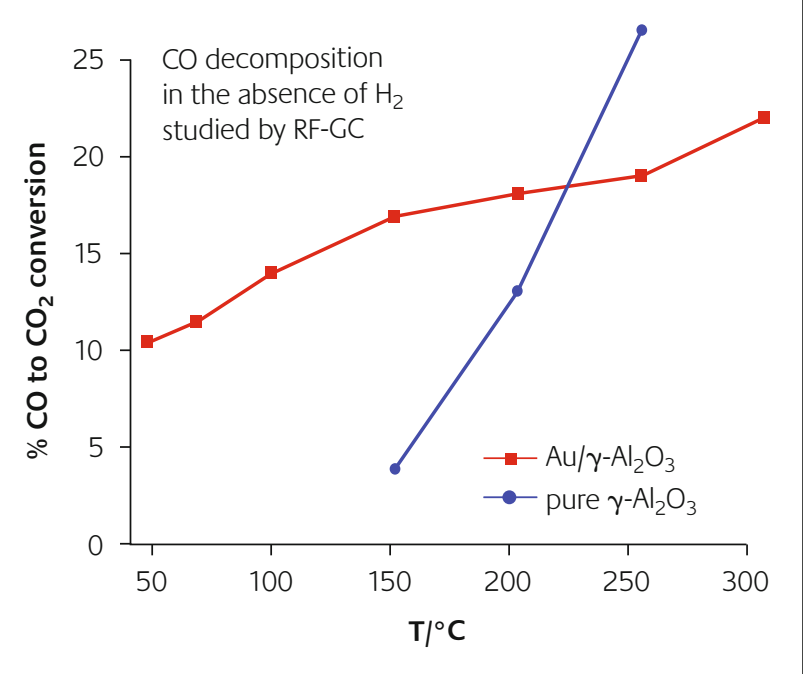

\section{Figure $3 b$}

b) Comparative study of $\mathrm{CO}$ decomposition over $\mathrm{Au} / \gamma-\mathrm{Al}_{2} \mathrm{O}_{3}$ catalyst and the support $\gamma-\mathrm{Al}_{2} \mathrm{O}_{3}(\bullet)$, measured, by reversed-flow gas chromatography
The interaction of pure CO with the studied catalyst, under continuous feeding conditions, was investigated by feeding a mixture of $4 \% \mathrm{vol}$. CO in helium. For each study, after stabilization at room temperature for 30 min two reaction cycles, each consisting of one heating and one cooling branch, were recorded to monitor hysteresis (if present) and catalyst (de)activation. After the last cooling stage, the catalyst was kept at room temperature for an extended period of time ( $\sim \mathrm{h})$ to evaluate the change in activity during time on stream. The second heating curve was found to be more representative for the "steady state" activity and was thus used for comparison of the catalysts. The experimental findings of this study are summarized in Figure 3a.

The conversion of $\mathrm{CO}$ to $\mathrm{CO}_{2}$ increases from $7 \%$ at ambient temperatures to $22 \%$ at $280^{\circ} \mathrm{C}$. In the case of the CO conversion experiments, a hysteresis was observed, in which the CO conversion in the cooling branch exceeded that of the heating branch at high temperatures $\left(>200^{\circ} \mathrm{C}\right)$. The opposite behaviour was observed at temperatures lower than $200^{\circ} \mathrm{C}$, at which $\mathrm{CO}$ conversion in the heating branch exceeded that of the cooling branch. At ambient conditions a constant activity varying from 7 to $11 \%$ was observed (c.f. Figure 3a).

A first obvious question arising from the experimentally observed $\mathrm{CO}_{2}$ formation in the absence of $\mathrm{O}_{2}$ is whether this activity is due to gold or the support. For this reason, similar experiments were carried out on the bare $\boldsymbol{\gamma}$-alumina support. Figure 3b summarizes the comparative activity study of $\mathrm{CO}_{2}$ formation over both $\mathrm{Au} / \gamma-\mathrm{Al}_{2} \mathrm{O}_{3}$ catalyst and bare $\gamma-\mathrm{Al}_{2} \mathrm{O}_{3}$. This study was carried out by RF-GC. A small amount of CO (1 $\mathrm{ml}$ under atmospheric pressure) was injected at the closed end of the diffusion column (c.f. Figure 2). Since each kinetic test is carried out at a constant temperature, the used methodology of RF-GC permits better equilibration of the catalytic activity. The experimental data obtained in the case of $\gamma-\mathrm{Al}_{2} \mathrm{O}_{3}$ show that the interaction of carbon monoxide in the absence of oxygen (carrier gas 100\% He) does not result in $\mathrm{CO}_{2}$ formation at temperatures lower than $150^{\circ} \mathrm{C}$. However, $\mathrm{CO}_{2}$ formation is detected above $150^{\circ} \mathrm{C}$ over bare $\mathrm{Al}_{2} \mathrm{O}_{3}$, significantly increasing with rising temperature, whereas over $\mathrm{Au} / \boldsymbol{\gamma}-\mathrm{Al}_{2} \mathrm{O}_{3}$, carbon dioxide formation is already observed in the temperature range $50-150^{\circ} \mathrm{C}$.

This is the first time that $\mathrm{CO}$ decomposition on $\mathrm{Au}$ nanoparticles is observed. However, for NO decomposition on Au surfaces was reported recently. It has been demonstrated before that certain stepped gold surfaces are able to form $\mathrm{N}_{2} \mathrm{O}$ from adsorbed $\mathrm{NO}(18)$ :

$$
2 \mathrm{NO} \rightarrow \mathrm{N}_{2} \mathrm{O}+\mathrm{O}_{\text {ads }}
$$

whereas the densely packed Au surfaces cannot decompose NO.

The main question is related to the mechanism responsible for the observed $\mathrm{CO}_{2}$ formation. A first possibility could be CO dissociation, as in the case over group VIII noble 
metals, such as: Pt, Rh, Pd etc (17). However, there is strong evidence both from experimental as well as theoretical studies that the adsorption of $\mathrm{CO}$, over even nanosized and defective Au particles, is too weak for CO dissociation (3$5,19,20)$. Moreover, $\mathrm{CO}_{2}$ formation, also observed over bare alumina, at temperatures higher than $150^{\circ} \mathrm{C}$, does not indicate the necessity of gold for the observed decomposition of $\mathrm{CO}$.

Alternatively, $\mathrm{CO}_{2}$ could be formed as the result of $\mathrm{CO}-\mathrm{CO}$ coupling, for example by formation of dicarbonyls on the surface. Bearing in mind the reductive pre-treatment of the catalyst and bare $\gamma-\mathrm{Al}_{2} \mathrm{O}_{3}$ with $\mathrm{H}_{2}$, the reaction of $\mathrm{CO}$ with surface hydroxyl, as in a step in water gas-shift reaction might seem much more likely. Costello et al. (8) studying the potential role of hydroxyl groups in $\mathrm{CO}$ oxidation over $\mathrm{Au} / \mathrm{Al}_{2} \mathrm{O}_{3}$ suggested a model of the active site involving an ensemble of metallic $\mathrm{Au}$ atoms and $\mathrm{Au}^{+}-\mathrm{OH}^{-}$. While there is spectroscopic evidence of the presence of Au cations in an active catalyst, although their role in the $\mathrm{CO}$ oxidation reaction is not accepted unequivocally (10), there is only inferential evidence of the presence and particularly the participation, of hydroxyl groups in the reaction (8). While the decomposition of $\mathrm{CO}$ at high temperatures, over bare $\gamma-\mathrm{Al}_{2} \mathrm{O}_{3}$ is probably related to Al-hydroxyls, the low temperature activity of $\mathrm{Au} / \boldsymbol{\gamma}-\mathrm{Al}_{2} \mathrm{O}_{3}$ for $\mathrm{CO}$ decomposition much more likely indicates that Au-hydroxyls are involved in the formation of $\mathrm{CO}_{2}$. However, a Au-OH group alone is not sufficient for $\mathrm{CO}$ decomposition. A corresponding reaction mechanism for the low temperature activity of $\mathrm{Au} / \gamma-\mathrm{Al}_{2} \mathrm{O}_{3}$ for CO decomposition might involve the insertion of $\mathrm{CO}$ into $\mathrm{Au}^{+}-\mathrm{OH}^{-}$to form Au-hydroxycarbonyl (8), which is then oxidized to a bicarbonyl, most probably interacting with O from neighbouring Al-hydroxyl. Decomposition of the bicarbonate removes a hydroxyl from $\mathrm{Al}$ and produces $\mathrm{CO}_{2}$ and Au-hydroxyl completing the reaction cycle.

The presence of surface hydroxyl groups is also supported from the experimental observation that water has a beneficial effect, enhancing the rate of CO oxidation over the studied $\mathrm{Au} / \gamma-\mathrm{Al}_{2} \mathrm{O}_{3}$ catalyst $(1,9,10)$, further indicating a reaction pathway in which surface $\mathrm{OH}$ groups can provide O needed for CO oxidation, in agreement with Haruta's observation that water on the catalyst is more important than water in the gas phase (21). Similarly, the presence of hydrogen in the feed has been found to cause changes in $\mathrm{CO}$ oxidation activity as those discussed for $\mathrm{H}_{2} \mathrm{O}$. Thus, it is not inconceivable that hydrogen is partly present as $\mathrm{H}_{2} \mathrm{O}$ or surface $\mathrm{OH}(1,9,10)$. Recently, there is reported spectroscopic evidence of the presence of cationic gold in the active catalysts (Ref. 8 and Refs. there in). In addition, although XRD, HRTEM and XPS measurements of the studied catalyst clearly point to the presence of metallic gold, the presence of traces of oxidic gold $\left(\mathrm{Au}_{2} \mathrm{O}\right.$ or $\left.\mathrm{Au}_{2} \mathrm{O}_{3}\right)$ has not been excluded $(1,9,10)$.

CO sorption processes are fundamental elementary steps for SCO and moreover, the effect of hydrogen on their sorption over supported Au catalysts remains a subject of significant interest. In a recent work, CO adsorption, desorption and surface bonding, were kinetically studied over silica supported monometallic $\mathrm{Rh}$ and $\mathrm{Rh}_{0.50}+\mathrm{Pt}_{0.50}$ alloy catalysts, under a wide range of hydrogen atmospheres: $25 \%-75 \% \mathrm{H}_{2}$, by means of RF-CC (14). The main finding of this work was a $\mathrm{H}_{2}$-induced desorption, which explains that described in the literature enhanced rate of SCO oxidation.

The interaction of carbon monoxide with the studied $\mathrm{Au} / \gamma-\mathrm{Al}_{2} \mathrm{O}_{3}$ catalyst can be outlined in a kinetic scheme, in which the elementary reversible steps of adsorption, $k_{1}$, and desorption, $k_{-1}$, are followed by carbon monoxide's surface bonding, $k_{2}$. Although, irreversible $\mathrm{CO}$ adsorption over $\mathrm{Au} / \mathrm{Al}_{2} \mathrm{O}_{3}$ has been reported (22), it is generally assumed that the noble nature of gold makes the strong chemisorption of $\mathrm{CO}$ (as well as $\mathrm{O}$ atoms and molecules) unlikely, even when low coordinated and defective Au atoms exist $(19,20)$.

\section{Table 1}

Rate constants for the adsorption, $k_{1}$, desorption, $k_{-1}$ and surface bonding, $k_{2}$, of CO over $A u / \gamma-A I_{2} O_{3}$ at various temperatures, in the absence as well as in excess of hydrogen, determined by RF-GC

\begin{tabular}{|c|c|c|c|c|c|c|c|}
\hline \multirow[t]{2}{*}{$\mathrm{T} /{ }^{\circ} \mathrm{C}$} & \multirow[t]{2}{*}{$\mathrm{T} / \mathrm{K}$} & \multicolumn{2}{|c|}{$10 \mathrm{k}_{1} / \mathrm{s}^{-1}$} & \multicolumn{2}{|c|}{$10^{4} \mathrm{k}_{-1} / \mathrm{s}^{-1}$} & \multicolumn{2}{|c|}{$10^{4} \mathrm{k}_{2} / \mathrm{s}^{-1}$} \\
\hline & & $0 \% \mathrm{H}_{2}$ & $75 \% \mathrm{H}_{2}$ & $0 \% \mathrm{H}_{2}$ & $75 \% \mathrm{H}_{2}$ & $0 \% \mathrm{H}_{2}$ & $75 \% \mathrm{H}_{2}$ \\
\hline 30 & 303 & - & 0.83 & - & 6.88 & - & 2.14 \\
\hline 40 & 313 & - & 0.97 & - & 6.35 & - & 2.23 \\
\hline 50 & 323 & 0.46 & 0.99 & 3.49 & 8.01 & 3.24 & 2.42 \\
\hline 60 & 333 & - & 1.00 & - & 8.13 & - & 2.50 \\
\hline 70 & 343 & 0.54 & 1.02 & 5.27 & 8.45 & 3.43 & 2.52 \\
\hline 80 & 353 & - & 1.08 & - & 9.28 & - & 2.59 \\
\hline 90 & 363 & - & 1.15 & - & 8.79 & - & 2.66 \\
\hline 100 & 373 & 0.82 & 1.25 & 6.78 & 8.84 & 3.65 & 2.70 \\
\hline 150 & 423 & 1.51 & 1.48 & 9.03 & 13.0 & 3.89 & 2.76 \\
\hline 200 & 473 & 1.97 & 1.70 & 10.1 & 17.9 & 4.35 & 2.87 \\
\hline 250 & 523 & 3.10 & 2.08 & 11.6 & 24.3 & 5.16 & 2.96 \\
\hline 300 & 573 & 5.95 & 2.64 & 13.9 & 28.0 & 6.03 & 3.23 \\
\hline
\end{tabular}


Consequently, in the present kinetic model, $k_{2}$, provides more a measure of the strength of $\mathrm{CO}$ bonding than of the reversibility or irreversibility of $\mathrm{CO}$ adsorption over the studied catalyst. The measured rates related to the effect of hydrogen on $\mathrm{CO}$ sorption over $\mathrm{Au} / \boldsymbol{\gamma}-\mathrm{Al}_{2} \mathrm{O}_{3}$ are summarized in Table 1.

The values of the found rates are comparable with those determined by Frequency Response Method for the adsorption of $\mathrm{CO}$ on silica supported Pt catalysts (23) ascertaining the potential of RF-GC for accurate and reliable kinetic measurements.

At low temperatures $\left(T<150^{\circ} \mathrm{C}\right), k_{1}$ values corresponding to $\mathrm{CO}$ adsorption over $\mathrm{Au} / \gamma-\mathrm{Al}_{2} \mathrm{O}_{3}$ under conditions of excess of hydrogen are higher than those in the absence of hydrogen. This behaviour is consistent with FTIR spectroscopy measurements concerning the low-temperature $\mathrm{CO}$ oxidation on $\mathrm{Au} / \gamma-\mathrm{Al}_{2} \mathrm{O}_{3}$, accordingly to which reduced in hydrogen samples were found to have higher $\mathrm{CO}$ adsorption capacity (24). At higher temperatures ( $>150^{\circ} \mathrm{C}$ ) adsorption rates in the absence of hydrogen are higher than those in excess of hydrogen, which may be related to the observed $\mathrm{CO}$ decomposition, which activity becomes more intense at temperatures higher than $150^{\circ} \mathrm{C}$. Moreover, the satisfactory selectivity of $\mathrm{Au} / \gamma-\mathrm{Al}_{2} \mathrm{O}_{3}$ for $\mathrm{SCO}$ at low temperatures can be further explained from the fact that the rate of adsorption is obviously higher in excess of hydrogen, due to the well known blocking or poisoning action of $\mathrm{CO}$, which prevents the dissociative adsorption of other gases, such as $\mathrm{O}_{2}$ and $\mathrm{H}_{2}(6,7)$.

In contrast, desorption rate values in excess of hydrogen are higher than those in the absence of hydrogen, indicating a beneficial influence of hydrogen on CO desorption rate. Carbon monoxide's desorption is considered as the determining step for the catalytic oxidation of $\mathrm{CO}$ on group VIII (Pt, Rh, Pd etc.) noble metal catalysts $(6,7,25)$. However, the beneficial influence of hydrogen on CO desorption is not determining for the low-temperature $\mathrm{CO}$ oxidation activity of gold, since it is generally assumed that the mild bonding character of gold is the basis of Au-based catalysts in oxidation processes at low temperatures $(19,20)$.

Jia et al. (22), recently observed two kinds of adsorbed CO on ulltrafine gold particles of a $\mathrm{Au} / \mathrm{Al}_{2} \mathrm{O}_{3}$ catalyst. The ultrafine gold particles catalyzed the oxidation of reversibly bonded $\mathrm{CO}$ at $150 \mathrm{~K}$, but did not convert the irreversible CO to $\mathrm{CO}_{2}$. The rate constants corresponding to $\mathrm{CO}$ surface bonding over the studied $\mathrm{Au} / \gamma-\mathrm{Al}_{2} \mathrm{O}_{3}$ catalyst in the absence of hydrogen, $k_{2}$, are obviously higher than those corresponding to the surface bonding of $\mathrm{CO}$ on the catalysts active sites, in excess of hydrogen, indicating the weaker and more reversible adsorption of $\mathrm{CO}$, in excess of hydrogen.

Rossignol et al. (26), suggest for the effect of hydrogen that beneficial effects of hydrogen on the CO oxidation reaction are mostly related to the prevention of deactivation and regeneration. In the presence of $\mathrm{H}_{2}$, two phenomena should occur simultaneously. One of these, having a negative effect on CO oxidation, is a competition of adsorption between $\mathrm{H}_{2}$ and $\mathrm{CO}$. The other one, which has a beneficial effect on CO oxidation, would be the appearance of additional reactive intermediates produced in the presence of $\mathrm{H}_{2}$. Furthermore, the presence of $\mathrm{H}_{2}$ in the $\mathrm{CO}+\mathrm{O}_{2}$ mixture not only prevents deactivation but also contributes via highly oxidizing intermediate species, such as $\mathrm{HO}-\mathrm{O}$ species, to the oxidation of $\mathrm{CO}$.

It is generally accepted that the high activity of nanosized $\mathrm{Au}$ for the low-temperature CO oxidation is due to its weak bonding ability with CO and atomic O $(19,20)$. Remediakis et al. (20), conclude that the presence of low-coordinated Au sites is crucial for CO oxidation. They identified two types of mechanisms for supported catalysts: i) Gold-only mechanisms for which the reaction takes place only on the nanoparticle, and ii) A second branch of support-assisted metal/oxide boundary mechanisms for which the reaction site is at the metal/oxide interface and the ensemble needed for $\mathrm{O}_{2}$ adsorption requires both low-coordinated Au atoms in the gold particle and other centers on the oxide.

Liu et al. (19), suggest that since, $\mathrm{O}_{2}$ dissociation $\left(\mathrm{O}_{2} \rightarrow 2 \mathrm{O}_{\mathrm{ad}}\right)$ on Au surfaces including particles is not expected at low temperatures, $\mathrm{CO}$ oxidation on Au/inactive-materials (e.g. $\gamma-\mathrm{Al}_{2} \mathrm{O}_{3}$ ) is expected to occur on Au steps via a two-step mechanism: a slow $\mathrm{CO}+\mathrm{O}_{2} \rightarrow \mathrm{CO}_{2}+\mathrm{O}$ reaction, and then a fast $\mathrm{CO}+\mathrm{O} \rightarrow \mathrm{CO}_{2}$ reaction. In general, the same mechanism can also describe selective $\mathrm{CO}$ oxidation in excess of hydrogen.

The beneficial effect of hydrogen concerning the low temperature $\mathrm{CO}$ oxidation can be similarly explained as result of the weakening of the strength of the $\mathrm{CO}$ and $\mathrm{O}_{2}$ bonding which intensifies the possibility of $\mathrm{CO}+\mathrm{O}_{2}$ reaction on $\mathrm{Au}$. In addition, $\mathrm{H}_{2}$ dissociation has been reported on $\mathrm{Au} / \mathrm{Al}_{2} \mathrm{O}_{3}$ (26). The adsorbed $\mathrm{H}$ atoms can also affect neighbour gold atoms in such a way that they can facilitate the activation of oxygen molecules (e.g. through $\mathrm{HO}-\mathrm{O}$ species) or directly react at the

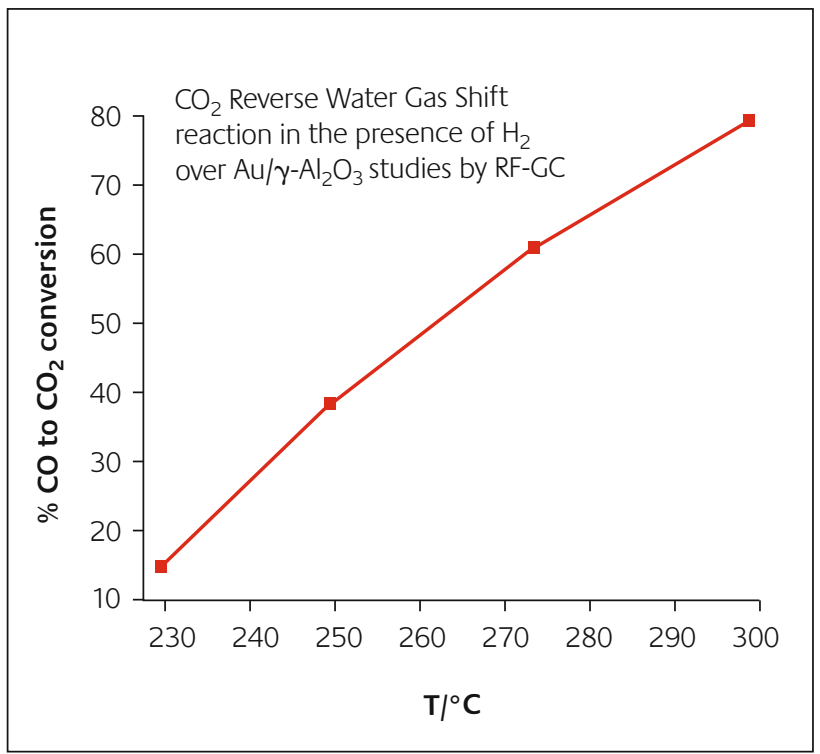

\section{Figure 4}

Temperature variation of $\mathrm{CO}$ formation due to $\mathrm{CO}_{2}$ Reverse Water Gas Shift reaction, in the presence of $\mathrm{H}_{2}$, over the same $\mathrm{Au} / \gamma-\mathrm{Al}_{2} \mathrm{O}_{3}$ catalyst, measured under non-continuous feeding conditions, by RF-GC 
perimeter of the Au nanoparticle with oxygen bound to the support (26). Hydrogen adsorption on gold, partly blocked at low temperatures by $\mathrm{CO}$, explains the high activity and satisfactory selectivity towards $\mathrm{CO}_{2}$ formation. At higher temperatures the $\mathrm{CO}$ desorption rate increases allowing more actives sites for $\mathrm{H}_{2}$ activation and reaction, resulting in loss of selectivity $(1,9,10)$. Similarly to hydrogen activation, the dissociative adsorption of oxygen on ensembles of metallic gold atoms becomes more important at higher temperatures, reducing the possibility of $\mathrm{CO}+\mathrm{O}_{2}$ reaction, while in the same time the possibility of hydrogen oxidation becomes more important. This is ought to the higher energy barrier of the hydrogen oxidation reaction $(\mathrm{O}+\mathrm{H} \rightarrow \mathrm{OH}$, $\left.\mathrm{H}+\mathrm{OH} \rightarrow \mathrm{H}_{2} \mathrm{O}, \mathrm{OH}+\mathrm{OH} \rightarrow \mathrm{H}_{2} \mathrm{O}+\mathrm{O}\right)$ compared to that of $\mathrm{CO}$ oxidation $\left(\mathrm{CO}+\mathrm{O} \rightarrow \mathrm{CO}_{2}\right)$ (27). Thus, while $\mathrm{CO}$ oxidation is more favored at lower temperatures, at higher temperatures hydrogen oxidation becomes more important, explaining the drastic decrease of SCO activity and selectivity.

The activity of $\mathrm{CO}$ selective oxidation in excess of hydrogen over the studied $\mathrm{Au} / \gamma-\mathrm{Al}_{2} \mathrm{O}_{3}$ catalyst is high (ranging from 95 to $80 \%$ ) at ambient temperatures $\left(<50^{\circ} \mathrm{C}\right)$, while it further decreases $(\sim 12 \%)$ at high temperatures. On the other side, the selectivity towards carbon monoxide oxidation is high only at low temperatures, while at higher temperatures hydrogen is consumed due to water formation. The drastic decrease of SCO activity and selectivity over the $\mathrm{Au} / \gamma-\mathrm{Al}_{2} \mathrm{O}_{3}$ catalyst is further explained from the experimentally observed reversed water gas shift (RWGS) reaction, occurring at high temperatures $\left(>200^{\circ} \mathrm{C}\right)$ in excess of $\mathrm{H}_{2}$. RWGS reaction results in $\mathrm{H}_{2}$ and $\mathrm{CO}_{2}$ consumption towards $\mathrm{CO}$ and $\mathrm{H}_{2} \mathrm{O}$ formation:

$$
\mathrm{CO}_{2}+\mathrm{H}_{2} \rightarrow \mathrm{CO}+\mathrm{H}_{2} \mathrm{O}
$$

The experimentally measured temperature variation of $\mathrm{CO}_{2}$ conversion towards $\mathrm{CO}$, in excess of $\mathrm{H}_{2}$, due to RWGS reaction over the studied $\mathrm{Au} / \gamma-\mathrm{Al}_{2} \mathrm{O}_{3}$, is shown in Figure 4.

\section{Conclusions}

New findings give further information on the mechanism of carbon monoxide selective oxidation over $\gamma-\mathrm{Al}_{2} \mathrm{O}_{3}$ supported nanoparticle sized Au catalysts. For first time is observed that the adsorption of $\mathrm{CO}$, over the studied $\mathrm{Au} / \gamma-\mathrm{Al}_{2} \mathrm{O}_{3}$ catalyst in the absence of oxygen, results in $\mathrm{CO}_{2}$ formation, pointing to a model of active sites consisting of an ensemble of metallic $\mathrm{Au}$ atoms and a cationic Au with a hydroxyl group. The presence of surface hydroxyl groups is also strengthened from the fact that water has a beneficial effect enhancing the rate of $\mathrm{CO}$ oxidation over the studied $\mathrm{Au} / \gamma-\mathrm{Al}_{2} \mathrm{O}_{3}$ catalyst, further indicating a reaction pathway in which surface $\mathrm{OH}$ groups can provide $\mathrm{O}$ needed for $\mathrm{CO}$ oxidation. The low temperature activity of $\mathrm{Au} / \boldsymbol{\gamma}-\mathrm{Al}_{2} \mathrm{O}_{3}$ for the so-called CO decomposition indicates that Au-hydroxyls are involved in the formation of $\mathrm{CO}_{2}$, which however are not sufficient for completing CO decomposition. A corresponding reaction mechanism suggested involving the insertion of $\mathrm{CO}$ into $\mathrm{Au}^{+}-\mathrm{OH}^{-}$to form Au-hydroxycarbonyl, which is then oxidized to a bicarbonyl, most probably interacting with $O$ from neighbouring Al-hydroxyl. Decomposition of the bicarbonate removes a hydroxyl from $\mathrm{Al}$ and produces $\mathrm{CO}_{2}$ and Au-hydroxyl completing the reaction cycle.

At lower temperatures $\left(\mathrm{T}<150^{\circ} \mathrm{C}\right)$, the rate of $\mathrm{CO}$ adsorption over $\mathrm{Au} / \boldsymbol{\gamma}-\mathrm{Al}_{2} \mathrm{O}_{3}$ in excess of hydrogen is higher compared to that in the absence of hydrogen, which is consistent with the observation that reduced in hydrogen samples have higher CO adsorption capacity. The rate of CO desorption is higher in excess of hydrogen, indicating a beneficial influence of hydrogen on CO desorption. In contrast, the rate constants corresponding to $\mathrm{CO}$ surface bonding over the studied $\mathrm{Au} / \gamma-\mathrm{Al}_{2} \mathrm{O}_{3}$ catalyst in the absence of hydrogen, $k_{2}$, are obviously higher than those corresponding to the surface bonding of $\mathrm{CO}$ on the catalysts active sites, in excess of hydrogen, indicating the weaker and more reversible adsorption of $\mathrm{CO}$.

Another observation of the present work is $\mathrm{CO}_{2}$ reversed water gas shift reaction, resulting in $\mathrm{H}_{2}$ and $\mathrm{CO}_{2}$ consumption towards $\mathrm{CO}$ and $\mathrm{H}_{2} \mathrm{O}$ formation, which also contributes to the drastic decrease of SCO activity and selectivity, at high temperatures $\left(\mathrm{T}>200^{\circ} \mathrm{C}\right)$.

\section{Acknowledgements}

D Gavril thanks World Gold Council for the financial support in the frame of a GROW sponsored project.

\section{References}

1 R.J.H. Grisel, B.E. Nieuwenhuys, J. Catal., 2001, 199, 48

2 M. Haruta, Catal. Today, 1997, 36, 153

3 L.M. Molina, B. Hammer, Phys. Rev. Lett., 2003, 90, 206102

4 M. Mavrikakis, P. Stoltze, J.K. Norskov, Catal. Lett., 2000, 64, 101

5 N. Lopez, T.V.W. Janssens, B.S. Clausen, Y. Xu, M. Mavrikakis, T. Bligaard, J.K. Norskov, J. Catal., 2004, 223, 232

6 S.H. Oh, S. Sinkevitch, J. Catal., 1993, 142, 254

7 M.J. Kahlich, H.A. Gasteiger, R.J. Behm, J. Catal., 1997, 171, 93

8 C.K. Costello, J.H. Young, H.-Y. Law, Y. Wang, J.-N. Lin, L.D. Marks, M.C. Kung, H.H. Kung, Appl. Catal. A, 2003, 6399, 1

9 R.J.H. Grisel, PhD Thesis Leiden University, The Netherlands, 2002

10 R.J.H. Grisel, C.J. Westrate, A. Goosens, M.W.J. Craje, A.M. van der Craan, B.E. Nieuwenhuys, Catal. Today, 2002, 72, 223

11 M. Haruta, N. Yamada, T. Kobayashi, S. lijima, J. Catal., 1989, 115, 301

12 P. Landon, J. Ferguson, B.E. Solsona, T. Garcia, A.F. Carley, A.A. Herzing, C.J. Kiely, S.E. Golunski, G.J. Hutchings, Chem. Commun, 2005, 27, 3385

13 S. Tsubota, T. Nakamura, K. Tanaka, M. Haruta, Catal. Lett., 1998, 56, 131

14 D. Gavril, V. Loukopoulos, A. Georgaka, A. Gabriel, G. Karaiskakis, J. Chromatogr. A, 2005, 1087, 158 
D. Gavril, B.E. Nieuwenhuys, J. Chromatogr. A, 2004, 1045, 161

16 V. Loukopoulos, D. Gavril, G. Karaiskakis, Instrum. Sci. Technol., 2003,

31, 165

17 D. Gavril, V. Loukopoulos, G. Karaiskakis, Chromatographia, 2004,

59, 721

18 C.P. Vinod, J.W. Niemantsverdriet, B.E. Nieuwenhuys, Apl.Catal. A, 2005, 291, 93

19 Z-P. Liu, P. Hu, A. Alavi, JACS, 2002, 124, 14770

20 I.N. Remediakis, N. Lopez, J.K. Norskov, Appl. Catal. A, 2005, 291, 13

21 M. Date, M. Haruta, J. Catal. 2001, 201, 221
22 105, 3017

23 Y.E. Li, D. Wilcox, R.D. Gonzalez, A/ChE J, 1989, 35, 423

24 R.J.H. Grisel, B.E. Nieuwenhuys, Catal. Today, 2001, 64, 69

25 B.E. Nieuwenhuys, Adv Catal, 1999, 44, 259

26 C. Rossignol, S. Arrii, F. Morfin, L. Piccolo, V. Caps, J.L. Rousset, J. Catal, 2005, 230, 476

27 S. Kandoi, A.A. Gokhale, L.C. Grabow, J.A. Dumesic, M. Mavrikakis, Catal. Lett., 2004, 93, 93 